ISSN 2409-5613 A. M. Murzakaev ${ }^{\mathrm{a}, \mathrm{b}}$, I. S. Zhidkov', S. O. Cholah ${ }^{\mathrm{b}}$, A. D. Maximov ${ }^{\mathrm{a}}$

${ }^{a}$ Institute of Electrophysics UB RAS, 106 Amundsen St., Yekaterinburg, 620016, Russian Federation

${ }^{b}$ Ural Federal University, 19 Mira St., Yekaterinburg, 620002, Russian Federation ${ }^{\star}$ E-mail: beketov@iep.uran.ru

\title{
Encapsulation of Ni nanoparticles with oxide shell in vapor condensation
}

Controlled input of oxygen into the inert working gas flow during the production of Ni nanoparticles by the electrical explosion of wire (EEW) method leads to the formation of a crystalline oxide shell on the surface of particles during their condensation from the vapor phase. Resulting oxide shells encapsulating $\mathrm{Ni}$ particles weaken their agglomeration processes as well as protect the surface of the Ni nanoparticles from further oxidation. The influence of the amount of energy introduced during EEW and the quantity of oxygen added to the working gas in EEW process on the properties of resulting Ni nanoparticles was studied. The obtained nickel nanopowders were characterized by $X$-ray diffraction (XRD), transmission electron microscopy (TEM), X-ray photoelectron spectroscopy (XPS), and $\mathrm{N}_{2}$ adsorption (BET) methods, which gave the specific surface area, the average diameter of nanoparticles, their phase composition, the morphology of the particles and the structure of the oxide shells. It was shown that the addition of oxygen leads to a decrease in the average diameter of $\mathrm{Ni}$ nanoparticles and reduces the degree of their agglomeration. The encapsulation of Ni nanoparticles with 3-5 nm thick gas-tight oxide shells protects the particles from oxidation and eliminates the pyrophoricity of the powder product.

Keywords: nickel nanoparticles, oxide shells, encapsulation, electrical explosion of wire.

Received: 10.07.2019. Accepted: 16.09.2019. Published: 15.10.2019.

(c) Beketov I. V., Safronov A. P., Medvedev A. I., Murzakaev A. M., Zhidkov I. S., Cholah S. 0., Maximov A.D., 2019

\section{Introduction}

Today, nanoparticles of transition metals are of considerable interest both from a scientific point of view due to their specific physical and chemical properties, and also in connection with promising practical applications [1]. In particular, such materials can be used as catalysts, as components in magnetic recording systems, in bioengineering and biomedicine, as components in sensors, actuators, scaffolds, etc.

With a decrease in particle size their surface activity considerably increases, promoting agglomeration and aggregation of particles, which complicates their 
further use. For instance, in the preparation of metal matrix composites or complex ceramic composites, the uniformity of the material is achieved only at the scale of agglomerates with sizes varying from units to tens of micrometers. Thus, the agglomeration of nanoparticles during their production limits the yield: with a decrease in the size of the particles, it is necessary to reduce the productivity of equipment to prevent their agglomeration. In addition, it is known that metal nanoparticles, with the exception of noble metals, are very pyrophoric at low temperatures and simply combust if exposed to ambient air. Usually, after the synthesis, the metal nanoparticles are passivated: a thin layer of oxide, which subsequently protects the metal from rapid oxidation, is formed on their surface. However, some metals, such as $\mathrm{Cu}$, even after the passivation do not form a gas-tight oxide shell that protects them from further oxidation. In particular, it is shown [2] that the process of oxidation of copper nanoparticles during their storage in air results in complete formation of $\mathrm{CuO}$.

To prevent agglomeration and to protect the surface of the particles, it is desirable to form protective shells on the particles during their formation. A choice of a material for a protective cover is a separate issue. On the one hand, the most acceptable material for the protective shell is a material that reliably protects the surface of the particle from rapid oxidation and does not interfere with, and in some cases even contributes to the further use of such powders. On the other hand, nanoparticles with the structure of the metal core - protective shell are typically used as fillers in composite polymer materials and liquid disperse systems. Therefore, the main property of the shell material is also to ensure the compatibility of core/shell nanoparticles with the dispersion medium, which depends on the energy of interaction between the dispersion medium and the surface of such nanoparticles.

In the technology of synthesis of metal nanoparticles, their surface is typically covered with pure carbon, silicon carbide, or polyethylene [3], which are not active at low temperatures. For instance, to create a carbon protective shell on the particles, various methods are used, such as annealing of metal particles in the atmosphere of hydrocarbon (gasoline) [4], filling carbon tubes with metal [5], annealing of a mixture of metal powder with carbon [6]. All these techniques involve the processing of the finished powder. The formation of a carbon shell on the surface of the particles in the process of synthesis of $\mathrm{Fe}, \mathrm{Co}$, Ni metal nanoparticles and their alloys using the method of an arc discharge in the methane atmosphere is described in Ref. [7].

In our opinion, nickel monoxide $(\mathrm{NiO})$ is a promising material of the protective shell for $\mathrm{Ni}$ nanoparticles. $\mathrm{NiO}$ has a relatively high melting point, $1955^{\circ} \mathrm{C}[8]$, and it forms a strong gas-tight protective film on the metal surface [9]. The objective of the present study is to develop an in-situ method of the formation of the protective oxide shells on the surface of Ni nanoparticles during their synthesis by the electric explosion of wire. Electric explosion of wire (EEW) is one of the most productive methods of synthesis of nanoparticles of metals, alloys and their chemical compounds. The productivity of EEW method ranges from 50 to $500 \mathrm{~g} / \mathrm{h}$ depending on the nature of nanoparticles. The method has low energy consumption, not exceeding $50 \mathrm{~kW} \cdot \mathrm{h} / \mathrm{kg}$; it is environmentally friendly; it provides high purity of the 
resulting particles. Experimental setups for EEW method are compact and do not

\section{Experimental}

Production of nickel nanopowders was carried out in the installation of an electric explosion of wire (EEW). The discharge circuit had an inductance of $0.4 \mu \mathrm{H}$. The capacitance of the capacitor bank varied from 3.2 to $4.8 \mu \mathrm{F}$, and the charging voltage - from 20 to $30 \mathrm{kV}$, which provided a change in overheating ratio $k$ (the ratio of the energy introduced into the wire to the sublimation energy of the wire metal) in the range of 1-2.2. To obtain the powder, a wire of nickel (NP2 grade) with a diameter of $0.3 \mathrm{~mm}$ and a length of 88 $\mathrm{mm}$ was used. The wire was fed into an explosion chamber continuously. Wire explosions were carried out in argon at a pressure of $0.12 \mathrm{MPa}$ at a frequency of $0.5 \mathrm{~Hz}$.

The gas system of the installation consisted of an explosion chamber, two inertial traps with a gas flow rotation, a mechanical (cloth) filter and a fan connected in series. Inertial traps were used to separate large micron-sized particles; the rest of the powder was collected in the filter. As shown by preliminary experiments, the output of the powder in the filter depends on the amount of energy introduced into the wire and averages $85 \%$ of the mass of all resulting from the explosion powder. Only the powders from the filter were studied in the present work. To create shells on the surface of the particles in the process of the powder production, oxygen was continuously introduced into the working gas (Ar) flow directly before entering the explosion chamber. With the help of an adjustable flow-type throttle, the oxygen flow could vary from 0.3 to $20 \mathrm{~cm}^{3} / \mathrm{s}$. For the ease of comparison of powders obtained in different modes, the amount of oxygen require separate facilities. This method has been described in detail elsewhere [10].

is given below in grams per gram of nickel (g/g Ni). At low oxygen consumption, after producing the powder, it was additionally passivated with oxygen flow $\left(0.5 \mathrm{~cm}^{3} / \mathrm{s}\right)$ supplied to the EEW setup. The minimum oxygen consumption, which allows eliminating the pyrophoricity of the powder, was determined experimentally. The passivation process was controlled by the oxygen partial pressure sensor. Passivation stopped when the partial pressure of oxygen reached $2 \mathrm{kPa}$. After that, the powder was freely (without the risk of its self-combustion) removed to the air.

The specific surface area of the obtained powders was determined by the BET method by low-temperature nitrogen adsorption using Micromeritics TriStar 3000. Xray phase analysis (XRD) was performed on the Bruker D8 DISCOVER diffractometer in $\mathrm{Cu}$ Ka radiation $(\lambda=1.54 \AA$ ) with a graphite monochromator on the secondary beam. Processing of diffractograms was performed using the program TOPAS 3. High-resolution transmission electron microscopy (TEM) was performed using the JEOL JEM2100 electron microscope at an accelerating voltage of $200 \mathrm{kV}$. The energy introduced into the wire was determined by the oscillograms of the current pulse passing through the exploding section of the wire. Measurements of the X-ray photoelectron spectroscopy (XPS) spectra of the main and valence levels of powders were carried out on the spectrometer PHI 5000 VersaProbe, based on the classical scheme of X-rays with a quartz monochromator and a hemispherical energy analyzer operating in the energy range from 0 to $1500 \mathrm{eV}$. Electrostatic focusing with 
magnetic shielding allows obtaining energy resolution $\Delta E \leq 0.5 \mathrm{eV}$ for $\mathrm{Al} \mathrm{Ka}$ radiation $(1486.6 \mathrm{eV})$. Pumping of the analytical chamber was carried out with the help of an ion pump, which provides a pressure lower than $10^{-7} \mathrm{~Pa}$. Two-channel neutralization was used to compensate the local surface charge formed during the measure- ments. The diameter of the X-ray spot was $200 \mathrm{mcm}$ and X-ray power $-50 \mathrm{~W}$. Calibration of spectra was carried out at the position of the 1s line of carbon $E=285.0 \mathrm{eV}$. Processing of XPS experimental data was carried out using the complex ULVAC-PHI MultiPak Software 9.8.

\section{Results and discussion}

The major variable to control the size of metal particles in EEW method is the overheating ratio $(k)$. It is a dimensionless coefficient, which is equal to the electrical energy introduced into a portion of a metal wire subjected to EEW divided by the energy of sublimation of this metal. In case of $\mathrm{Ni}$, the energy of sublimation is $65.1 \mathrm{~J} / \mathrm{mm}^{3}$. The experimental dependence of the specific surface area and the mean diameter of Ni nanoparticles on overheating coefficient are shown in Fig. 1. The mean diameter of spherical particles $(D)$ is related to the value of their specific surface area $\left(S_{s p}\right)$ by the following equation:

$$
D=6 / \rho \cdot S_{s p}
$$

with $\rho$ being the effective density of the material $\left(\mathrm{Ni}-8.91 \mathrm{~g} / \mathrm{cm}^{3}, \mathrm{NiO}-7.45 \mathrm{~g} / \mathrm{cm}^{3}\right)$.

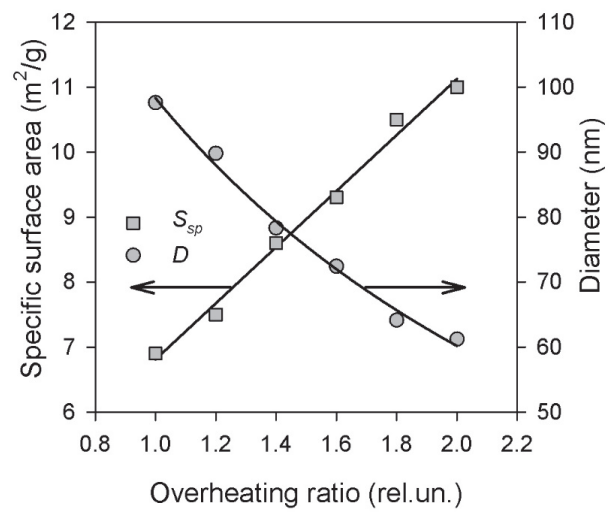

Fig. 1. The dependence of the specific surface area (left) and the average diameter (right) of Ni nanoparticles synthesized by EEW method on the overheating ratio
It is seen that the specific surface area of Ni nanoparticles substantially increases from around $7 \mathrm{~m}^{2} / \mathrm{g}$ up to $11 \mathrm{~m}^{2} / \mathrm{g}$ if the overheating ratio is doubled. Consequently, with the increase in the overheating ratio, the diameter of Ni particles diminishes from 100 down to $60 \mathrm{~nm}$ in average. Further on, the results for two values of the overheating ratio will be systematically compared. These values are $k=1.2$, which corresponds to large Ni particles (low specific surface area) and $k=2$ (small particles, high specific surface area). It is worth noting that overheating ratio $k=1$ was not taken, because of the technical difficulties of maintaining stable EEW process at zero overheating.

Using the given levels of overheating ratio, several batches of Ni particles were synthesized with the controlled addition of oxygen to the EEW installation. The crystalline structure of obtained $\mathrm{Ni}$ nanoparticles was characterized by XRD. Fig. 2 , $a$ gives examples of XRD diffractograms for two Ni batches synthesized at different amount of oxygen added to the working gas of the EEW installation. In both cases, two cubic phases were identified: the major one corresponded to $\mathrm{Ni}$ with lattice parameter $a=3.523(1) \AA$ and the minor one corresponded to $\mathrm{NiO}$ with $a=4.174(2) \AA$. It means that the addition of oxygen to the working gas resulted in the in-situ oxidation of condensed Ni nanoparticles. Fur- 
ther on, the obtained particles, which contain both the fraction of metallic $\mathrm{Ni}$ and $\mathrm{NiO}$ are denoted as Ni@NiO.

Using the diffractograms, the weight fraction of $\mathrm{NiO}$ in all batches was evaluated. The dependence of $\mathrm{NiO}$ content in nanoparticles on the amount of oxygen added to the working gas in EEW installation is given in Fig. 2, $b$. The amount of oxygen (in weight) is divided by the weight of $\mathrm{Ni}$ wire consumed in the synthesis. Further on it is denoted as Q. Experimental points in Fig. 2, $b$ relate to two values of overheating ratio, $k=1.2$ and $k=2$.

It is seen that, despite the difference in the level of overheating ratio, the experimental points can be fitted well with the same linear dependence, $\% \mathrm{NiO}=$ 302.Q. It means that in-situ oxidation does not depend on the average diameter of $\mathrm{Ni}$ particles and is governed exclusively by the amount of oxygen in the working gas.

Fig. 3 presents experimental dependences of the specific surface area (Fig. 3, a)
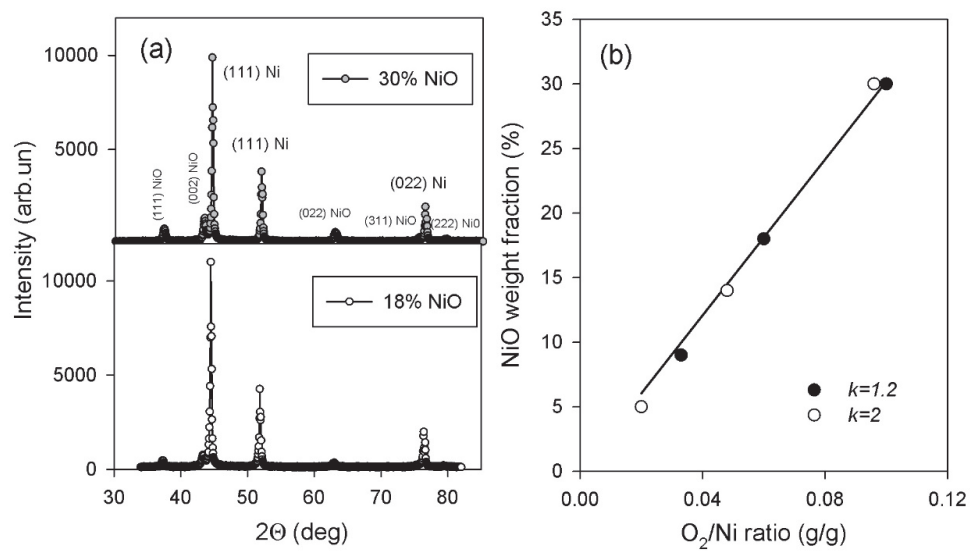

Fig. 2. $a$ - Selected XRD diffraction patterns of EEW Ni nanoparticles synthesized with the addition of oxygen; $b$ - Dependence of $\mathrm{NiO}$ weight fraction on the amount of oxygen added to EEW synthesis per Ni wire consumption. Closed circles correspond to overheating ratio 1.2, open circles - to overheating ratio 2
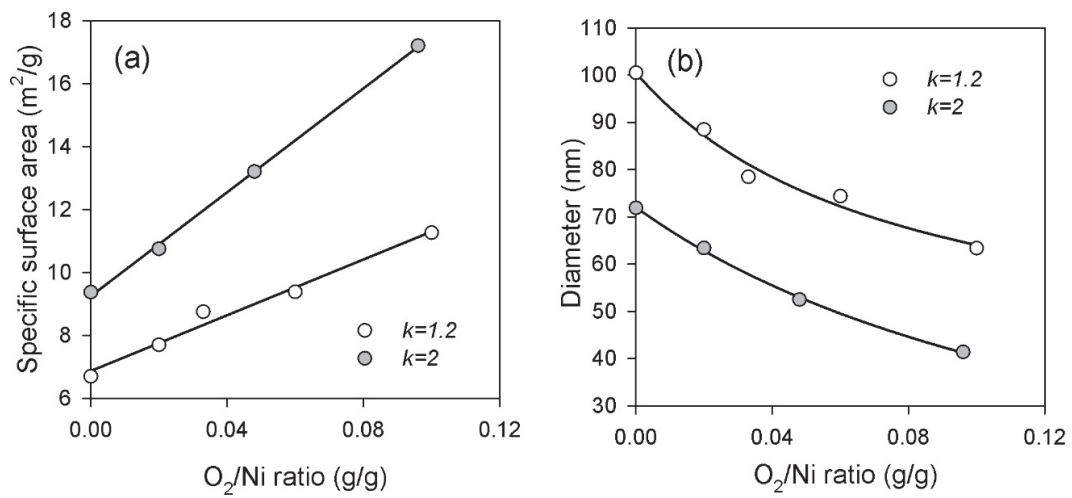

Fig. 3. Dependence of the specific surface area $(a)$ and mean diameter $(b)$ of Ni particles on the amount of oxygen introduced into EEW installation during the synthesis at overheating ratios 
and the average diameter of nanoparticles (Fig. 3, b) on the amount of oxygen added to the working gas of the EEW installation at the values of overheating ratio equal to 1.2 and 2.

As shown in Fig. 3, $a$, the increase in oxygen consumption leads to an increase in the specific surface area of produced $\mathrm{Ni}$ nanoparticles at both levels of overheating ratio. The experimental plots are nicely fitted by the linear dependences: $6.9+44.2 \cdot Q$ $\left(R^{2}=0.981\right)$ for $k=1.2$ and $9.2+82.4 \cdot Q$ $\left(R^{2}=0.998\right)$ for $k=2$. In general, the increasing trend in specific surface area due to the addition of oxygen is equivalent to the same trend due to the increase in overheating ratio (see Fig. 1). It is because the oxidation of $\mathrm{Ni}$ to $\mathrm{Ni}$ oxide is accompanied with the evolution of heat, which adds up to the electric energy introduced in EEW. Thus, the total amount of energy (electrical and oxidation) in EEW process exceeds the sublimation energy of $\mathrm{Ni}$ significantly more in the presence of oxygen than in the inert atmosphere.

Fig. 3, $b$ presents the average diameter of Ni@NiO particles as a function of oxygen/Ni ratio. The average diameter was calculated using Eq. (1) taking into account that the density of $\mathrm{Ni@NiO} \mathrm{particles} \mathrm{di-}$ minishes with the increase of $\mathrm{NiO}$ content due to the difference in densities of $\mathrm{Ni}$ and $\mathrm{NiO}$. It is seen that, at both levels of overheating ratio, the decreasing trend in the average diameter of $\mathrm{Ni@NiO} \mathrm{particles} \mathrm{is}$ observed. The reason is the same as for the increasing trend of the specific surface area. The oxidation reaction provides extra energy to the system, and the overheating effectively increases.

It is noticeable that the slopes of the linear plots in Fig. 3, $a$ are different for two levels of overheating. The slope coefficient is 44.2 if $k=1.2$, and it is 82.4 if $k=2$.
However, no evident difference in the slopes of plots can be noticed in Fig. 3, $b$. It is because the calculation of the average diameter of Ni@NiO particles according to Eq. (1) includes the partial correction of increasing $S_{\mathrm{sp}}$ values by the decreasing density of $\mathrm{Ni@NiO} \mathrm{particles} \mathrm{with} \mathrm{the}$ increase in their oxidation. The plots are shifted one against the other by the initial difference of average particle diameter for $k=1.2$ (smaller particles) and $k=2$ (larger particles).

It is known [9] that in the oxidizing atmosphere the surface of metallic $\mathrm{Ni}$ is covered with dense oxide layer which efficiently prevents metal from further oxidation. The Pilling-Batworth criterium [11] for $\mathrm{NiO}$ is 1.52 , which means that Ni particles should be covered with dense oxide shell in the presence of oxygen. During EEW, the formation of oxide shells on the surface of Ni particles can start only at the moment when the expanding cloud of metal vapor after the explosion mixes up with the working gas, which contains oxygen. It does not take place at the very first moments after the explosion, as the expanding cloud of vapors is substantially denser than the surrounding working gas. Furthermore, the critical temperature of the thermodynamic stability of $\mathrm{NiO}$ is lower than the temperature of condensation of $\mathrm{Ni}$ vapors into liquid phase. Therefore, oxidation begins when the condensation on $\mathrm{Ni}$ liquid droplets has been already completed, and it takes place at the surface of $\mathrm{Ni}$ particles (liquid or solid). Fig. 4 presents high-resolution TEM image of the surface of $\mathrm{Ni}$ particle synthesized in the presence of oxygen.

It is clearly noticeable that the surface of a particle is covered with a layer, whose crystal structure is different from that of the interior of the particle. The lattice 
period in the surface layer evaluated from HRTEM images is $2.4 \pm 0.1 \AA$. This value corresponds to the lattice period for cubic or rhombohedric $\mathrm{NiO}$ structure. According to XPS analysis, the spectrum of the surface of Ni particles synthesized in the presence of oxygen contained signals of elements $\mathrm{Ni}$ and $\mathrm{O}$. $\mathrm{Ni}$ is present in the oxidation state $\mathrm{Ni}^{+2}$, which is an indication of $\mathrm{NiO}$ [12], and $\mathrm{Ni}^{+3}$, which likely corresponds to $\mathrm{Ni}_{2} \mathrm{O}_{3}$ [13] or $\mathrm{NiOOH}$ [14]. The surface also contained carbon, which is the result of carbon dioxide adsorption from the air.

The thickness of oxide layers on $\mathrm{Ni}$ particles was evaluated by the graphical analysis of TEM images obtained with $3.7 \cdot 10^{6}$ and $7.4 \cdot 10^{6}$ magnification. The average values of the thickness of oxide layers are given in Table 1. According to Table 1 , the thickness of oxide layers increases with the increase in the amount of oxygen added to working gas in EEW process. At the same time, the overheating ratio does not make a noticeable influence.

Table 1

Average thickness of oxide layer on Ni@NiO particles

\begin{tabular}{c|c|c}
\hline $\begin{array}{c}\mathrm{Q}_{\mathrm{O} 2}, \\
\mathrm{~g} / \mathrm{g} \mathrm{Ni}\end{array}$ & $\begin{array}{c}\text { Overheating, } \\
k\end{array}$ & $\begin{array}{c}\text { Thickness, } \\
\mathrm{nm}\end{array}$ \\
\hline 0.03 & 1.2 & 2.51 \\
\hline 0.1 & 1.2 & 3.35 \\
\hline 0.02 & 2 & 2.82 \\
\hline 0.096 & 2 & 3.31
\end{tabular}

Like other chemical reactions in the EEW process, oxidation of $\mathrm{Ni}$ surface takes place in non-equilibrium conditions. It results in the non-uniformity of $\mathrm{NiO}$ distribution on the surface of $\mathrm{Ni@NiO} \mathrm{particles.}$ It becomes more evident at large amounts of added oxygen. Fig. 5 presents TEM image of $\mathrm{Ni@NiO} \mathrm{particles} \mathrm{obtained} \mathrm{at}$ $Q_{\mathrm{O}_{2}}=0.1 \mathrm{~g} / \mathrm{g} \mathrm{Ni}$.

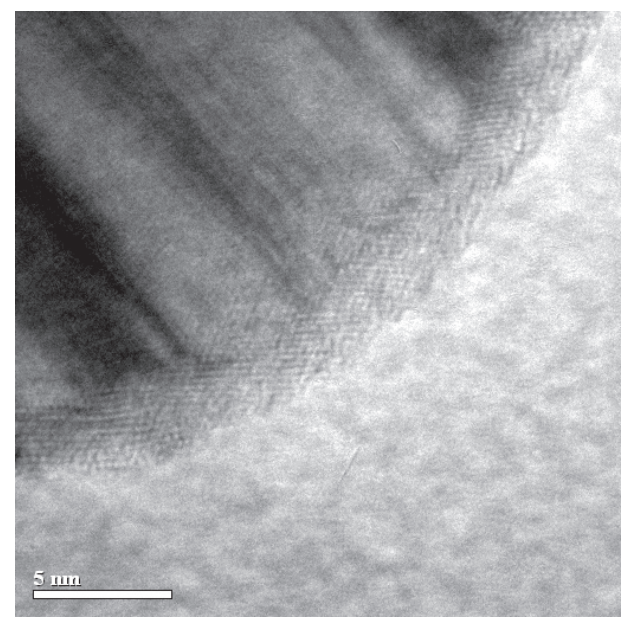

Fig. 4. High-resolution TEM image of $\mathrm{Ni}$ particle synthesized by EEW at $k=1.2$;

$$
Q_{\mathrm{O} 2}=0.033 \mathrm{~g} / \mathrm{g} \mathrm{Ni}
$$

It is noticeable in Fig. 5, $a$ that the spherical shape of Ni@NiO particles became substantially distorted due to the formation of oxide layers with varied thickness. Most likely, it is because oxidation took place at elevated temperature before the particles were cooled down to the ambient temperature. In these conditions of intense non-equilibrium oxidation, the initially formed oxide layer could be fractioned, and spherical shape of particles would be distorted. Such distortions might as well be taken as evidence in favor of oxidation of $\mathrm{Ni}$ in liquid droplets, whose surface is easier to distort, rather than condensed solid particles.

At the high level of oxygen in the working gas, the smallest Ni particles, which are the most chemically active, could transform completely into NiO. Fig. 5, $b$ shows such a particle with a diameter of $15 \mathrm{~nm}$, which is completely formed by $\mathrm{NiO}$. The fragment of crystal lattice noticeable in Fig. 5, $b$ has a lattice period of $2.4 \pm 0.1 \AA$, which corresponds to $\mathrm{NiO}$. Due to the presence of separate $\mathrm{NiO}$ particles and thickened oxide layers, the total $\mathrm{NiO}$ content in $\mathrm{Ni@}$ 
$\mathrm{NiO}$ particles according to XRD increases up to $30 \%$ if oxygen content in the working gas is raised up to $0.1 \mathrm{~g} / \mathrm{g} \mathrm{Ni}$.

As the oxidation of Ni likely takes place on the surface of liquid droplets, the formation of solid oxide layer can prevent the coalescence of droplets, which causes agglomeration of particles in the product powder. Fig. 6 illustrates the influence of oxygen addition on agglomeration.

In Fig. 6, $a$ it is evident that agglomeration of Ni particles is high. Almost all of them in the image are bonded into one cluster, which is certainly the result of coalescence of liquid Ni droplets in gas phase at temperatures above crystallization. Con-

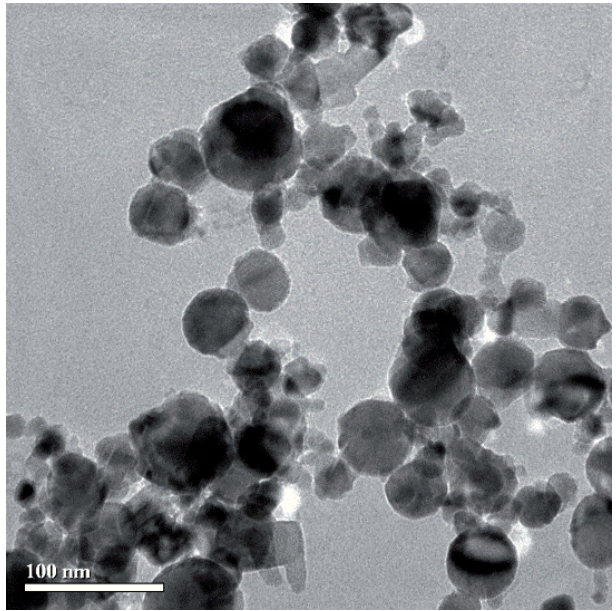

$a$

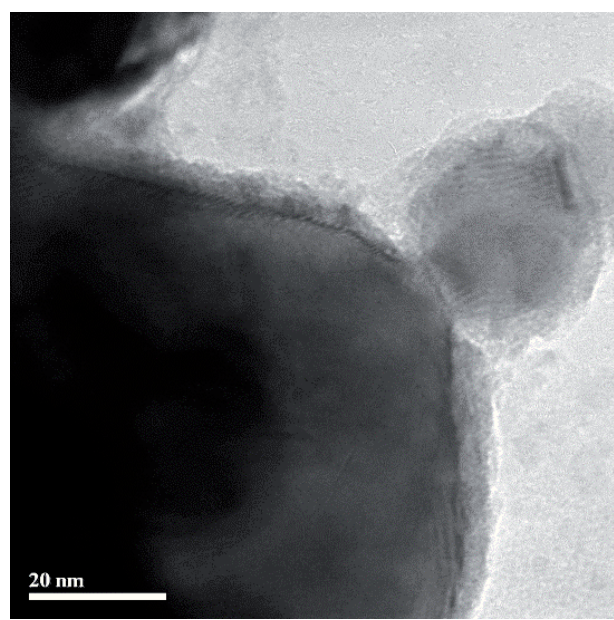

$b$

Fig. 5. $a-\mathrm{Ni@NiO} \mathrm{particles} \mathrm{obtained} \mathrm{by} \mathrm{EEW} \mathrm{at} Q_{\mathrm{O} 2}=0.1 \mathrm{~g} / \mathrm{g} \mathrm{Ni}, k=1.2 ; b-$ High resolution TEM image of the surface with $\mathrm{NiO}$ layer and small separate $\mathrm{NiO}$ particle $(\mathrm{D}=15 \mathrm{~nm})$

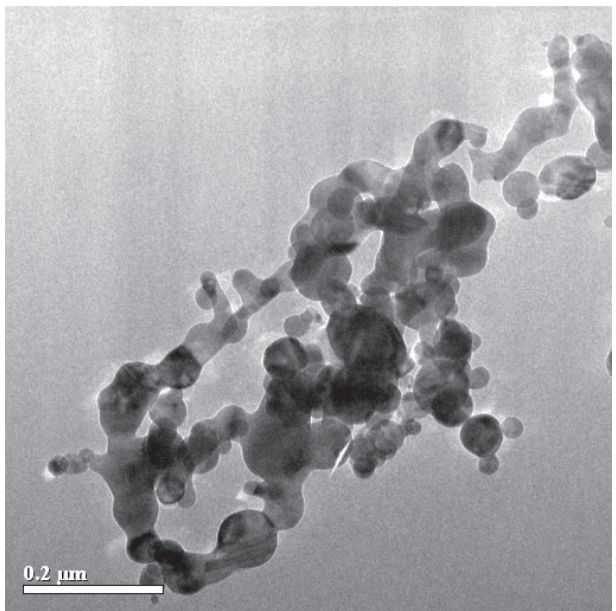

$a$

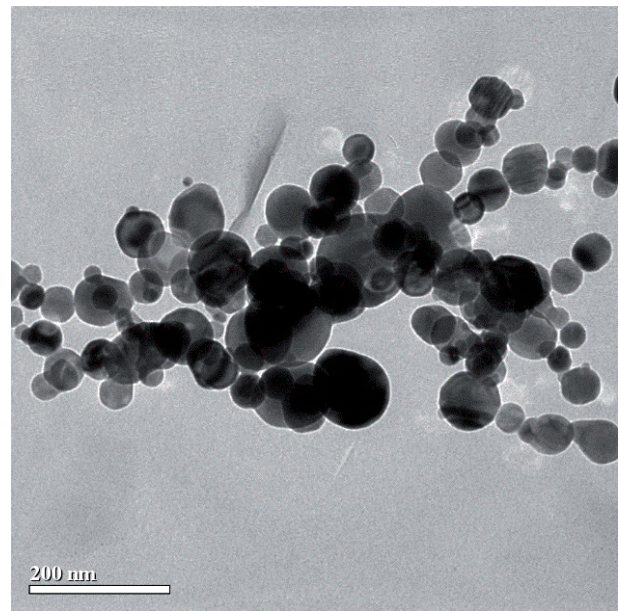

$b$

Fig. 6. $a-\mathrm{Ni}$ nanoparticles synthesized in argon; $b-\mathrm{Ni@NiO} \mathrm{nanoparticles} \mathrm{synthesized}$ in argon with the addition of oxygen, $Q_{\mathrm{O} 2}=0.033 \mathrm{~g} / \mathrm{g} \mathrm{Ni}$ 
trary to that, the majority of $\mathrm{Ni@NiO} \mathrm{na-}$ noparticles in Fig. 6, $b$ are separated from each other. Even if we see them on top of one another, we can also see distinct spherical boundaries. It means that Ni@ $\mathrm{NiO}$ particles are individual. Some agglomeration can still be noticed, but it is not predominant in case of Ni@NiO particles. The residual agglomeration of $\mathrm{Ni@NiO} \mathrm{stems}$ from the large difference - $1223 \mathrm{~K}-$ between the temperature of vaporization of $\mathrm{Ni}, 3173 \mathrm{~K}$ [15], and the upper temperature of oxidation, $1950 \mathrm{~K}$ (calculated using the software Chemical WorkBench, ver. 3, Kinetic Technologies Ltd.). This temperature interval provides a time gap from the moment when liquid droplets of $\mathrm{Ni}$ condense from the vapor phase until they are covered with solid oxide, which prevents their coalescence. In case of other metals,

\section{Conclusions}

The controlled oxygen injection into the inert working gas of the EEW unit during the production of Ni powder makes it possible to form a crystalline oxide shell on the particles in the process of their formation. It depresses the particle agglomeration, as well as protects the surface of $\mathrm{Ni}$ particles from oxidation. The increase in oxygen consumption leads to an increase in the specific surface area of the powder. In the range of oxygen consumption from 0 to $0.1 \mathrm{~g} / \mathrm{g} \mathrm{Ni}$, the specific surface area varies almost linearly and increases by 60 $80 \%$ depending on the overheating ratio.

Addition of oxygen to the working gas leads to the formation of a separate phase in the powdered product - crystalline $\mathrm{Ni}$ oxide, the content of which increases with increasing oxygen consumption. At low this interval is narrower: $\mathrm{Al}-350-400 \mathrm{~K}$, $\mathrm{Cu}-500 \mathrm{~K}$. In case of these metals, the addition of oxygen prevents agglomeration completely. Nevertheless, despite the large temperature interval before oxidation, the addition of oxygen substantially decreases agglomeration of Ni nanoparticles.

$\mathrm{NiO}$ layers on the surface of Ni nanoparticles substantially enhance their stability to self-combusting in the air. It was found experimentally that at an oxygen consumption greater than $0.015 \mathrm{~g} / \mathrm{g} \mathrm{Ni}$, the powdered product can be transferred from the EEW setup to the ambient air without the risk of combustion. Such oxygen additition leads to a significant reduction in the pyrophoricity of the powder, as $\mathrm{Ni@NiO}$ particles are covered with an oxide shell that reliably protects them from oxidation during storage.

consumption of oxygen, $\mathrm{NiO}$ forms a dense crystalline shell on the surface of particles. The thickness of the shell is $2-5 \mathrm{~nm}$ and increases with increasing oxygen consumption. Overheating ratio has no significant effect on the shell thickness. In the range of oxygen consumption $0-0.1 \mathrm{~g} / \mathrm{g}$ Ni the content of $\mathrm{NiO}$ linearly increases up to $30 \%$ independently of overheating ratio. At high oxygen consumption, spherical shape of Ni@NiO nanoparticles is substantially distorted, and small separate individual $\mathrm{NiO}$ nanoparticles tend to appear. When the oxygen consumption is larger than $0.015 \mathrm{~g} / \mathrm{g} \mathrm{Ni}$, the powdered product becomes non-pyrophoric and can be subjected to the ambient air without the risk of combustion. 


\section{Acknowledgements}

This work was performed as part of State Task of IEP UB RAS and by RAS Program Project No. 18-10-2-38. The study was performed using the equipment of the Center for the common research of IEP UB RAS and using the X-ray spectrometer of the Chair of Electrophysics of the Physical Technological Institute of the Ural Federal University.

\section{References}

1. Gusev AI. Nanomaterialy, nanostructury, nanotekhnologii. Moscow: Fizmatlit, 2005. 416 p. Russian.

2. Kotov YuA, Rhee ChK, Beketov IV, Bagazeyev AV, Demina TM, Murzakayev AM, Samatov OM, Timoshenkova OR, Medvedev AI, Shtols AK. Production of Copper Nanopowders by Electric Explosion of Wire-Study of Their Oxidation during Storage and Heating in Air. Journal of Metastable and Nanocrystalline Materials. 2003;15-16:343-8.

DOI: 10.4028/www.scientific.net/JMNM.15-16.343.

3. Athanassiou EK, Grass RN, Stark WJ. Large-scale production of carbon-coated copper nanoparticles for sensor applications. Nanotechnology. 2006;17(6):1668-73. DOI: $10.1088 / 0957-4484 / 17 / 6 / 022$.

4. Hayashi C. Ultrafine particles. Journal of Vacuum Science \& Technology A. 1987;5(4):1375-84.

DOI: $10.1116 / 1.574773$.

5. Tsang SC, Chen YK, Harris PJF, Green MLH. A simple chemical method of opening and filling carbon nanotubes. Nature. 1994;372(6502):159-62.

DOI: $10.1038 / 372159 \mathrm{a} 0$.

6. Tomita S, Hikita M, Fujii M, Hayashi S, Akamatsu K, Deki S, Yasuda H. Formation of Co filled carbon nanocapsules by metal-template graphitization of diamond nanoparticles. Journal of Applied Physics. 2000;88(9):5452-6.

DOI: $10.1063 / 1.1317242$.

7. Zhang ZD, Zheng JG, Skorvanek I, Wen GH, Kovac J, Wang FW, Yu JL, Li ZJ, Dong XL, Jin SR, Liu W, Zhang XX. Shell/core structure and magnetic properties of carbon-coated $\mathrm{Fe}-\mathrm{Co}(\mathrm{C})$ nanocapsules. Journal of Physics: Condensed Matter. 2001;13(9):1921-9.

DOI: 10.1088/0953-8984/13/9/314.

8. Wartenberg HV, Reusch HJ, Saran E. Schmelzpunktsdiagramme höchstfeuerfester Oxyde. VII. Systeme mit $\mathrm{CaO}$ und $\mathrm{BeO}$. Zeitschrift für anorganische und allgemeine Chemie. 1937;230(3):257-76. German.

DOI: $10.1002 /$ zaac. 19372300309 .

9. Evans UR. Corrosion and Oxidation of Metals. London: Edward Arnold Ltd., 1960. $324 \mathrm{p}$.

10. Kotov YA. Electric Explosion of Wires as a Method for Preparation of Nanopowders. Journal of Nanoparticle Research. 2003;5(5):539-50.

DOI: 10.1023/B:NANO.0000006069.45073.0b.

11. Pohil PF, Belyaev AF et al. Gorenie poroshkoobraznykh metallov v aktyivnykh sredakh. Moscow: Nauka, 1972. 294 p. Russian. 
12. Payne BP, Biesinger MC, McIntyre NS. The study of polycrystalline nickel metal oxidation by water vapour. Journal of Electron Spectroscopy and Related Phenomena. 2009;175(1):55-65.

DOI: 10.1016/j.elspec.2009.07.006.

13. Weidler N, Schuch J, Knaus F, Stenner P, Hoch S, Maljusch A, Schäfer R, Kaiser B, Jaegermann W. X-ray Photoelectron Spectroscopic Investigation of Plasma-Enhanced Chemical Vapor Deposited $\mathrm{NiO}_{x}, \mathrm{NiO}_{x}(\mathrm{OH})_{y}$, and $\mathrm{CoNiO}_{x}(\mathrm{OH})_{y}$ : Influence of the Chemical Composition on the Catalytic Activity for the Oxygen Evolution Reaction. Journal of Physical Chemistry C. 2017;121(12):6455-63.

DOI: $10.1021 /$ acs.jpcc.6b12652.

14. Leedahl B, Boukhvalov DW, Kurmaev EZ, Kukharenko A, Zhidkov IS, Gavrilov NV, Cholakh SO, Huu Le P, Wei Luo C, Moewes A. Bulk vs. Surface Structure of 3d Metal Impurities in Topological Insulator $\mathrm{Bi}_{2} \mathrm{Te}_{3}$. Scientific Reports. 2017;7(1):5758. DOI: 10.1038/s41598-017-06069-3.

15. Perel'man FM, Zvorykin AYa. Kobalt i nikel. Moscow: Nauka, 1975. 215 p. Russian. 